\title{
A Mathematical Formalization Proposal for Business Growth
}

\author{
Gheorghe BĂILEŞTEANU, Diana TÂRNĂVEANU \\ West University of Timişoara, Faculty of Economics and Business Administration, \\ Timişoara, Romania \\ gheorghe.bailesteanu@feaa.uvt.ro,diana.tarnaveanu@feaa.uvt.ro
}

\begin{abstract}
Economic sciences have known a spectacular evolution in the last century; beginning to use axiomatic methods, applying mathematical instruments as a decision-making tool. The quest to formalization needs to be addressed from various different angles, reducing entry and operating formal costs, increasing the incentives for firms to operate formally, reducing obstacles to their growth, and searching for inexpensive approaches through which to enforce compliancy with government regulations. This paper proposes a formalized approach to business growth, based on mathematics and logics, taking into consideration the particularities of the economic sector.
\end{abstract}

Keywords: Formalization, Symbolism, Business Growth, Axioms, Theorems

\section{1} Introduction

Introduced by the Greeks, the meaning of the word axiom was of something worthy or which commends itself as evident. In time, the meaning has changed into fundamental truth, admitted without proof. All the definitions are based on the idea of truth and beginning. According to Oxford dictionary, an axiom is "a statement or proposition which is regarded as being established, accepted, or self-evidently true" [1]. An axiom can also be considered as a primary object, without proof, based on which other objects can be deduced [2]. It can be added that other statements or theorems can be developed based on axioms and reasoning. On a scientific approach, an axiom is a stand-alone statement regarding some initial terms or basic concepts that are not and cannot be defined. In an axiomatic system, the primary terms are those that are not explicitly defined. From that perspective, axioms can be characterized as "propositional expressions based on primitive terms or admitted to be true at a specific moment" [3]. In the contemporary meaning, an axiom is a primary statement considered to be true without proof, self-evident and which in other system can be considered as a theorem [4]. In the traditional manner, sometimes it is accepted that "a" exists in an absolute sense (a statement that cannot be proof but it is obvious), while from the contemporary logic point of view "a" exists relatively (an axiom in $\mathrm{S}$, where $\mathrm{S}$ is an axiomatic system). The functioning of a statement as an axiom has a relative value; in an organization or a theoretical expose a statement can be an axiom, in another it can be a consequence or a theorem.

Axiomatizing is a method of systematizing statements from an information domain [5]. It assumes the following principles:

- postulates a finite number of terms (objects) called primary terms and the definition rules of the other terms (objects) derived from the primary ones (derived terms);

- postulates a finite number of primary statements called axioms and the reasoning leading to other statements (called theorems). As a result an axiomatic system is obtained. If the objects are formal, than a formal axiomatic system is obtained.

Formal systems integrate a certain domain of human knowledge experiences. They are a construction, an ensemble of production rules and selecting a sum of symbols, a mechanism that produces symbols and expressions.

A formal system is a system of formal objects (graphical symbols) with whom it operates based on forming, transforming and selection rules. Formal is a word derived from "formalization" or syntax "representation" of a formalized language. 
The criteria of a formal system are:

a) given a set of primary formal objects (graphical symbols) of different category (each category being determined based on the role the object will play);

b) given a set of rules, that help forming finite sequences of statements;

c) a set of primary statements called "axioms";

d) given a set of rules (of transforming and selection):

- a sequence is transformed into another sequence through certain operations;

- based on axioms, selection and reasoning rules, certain sequences can be selected, called theorems. These criteria are sufficient to build a formal system constituted by a set of axioms and a set of theorems. In order to differentiate a formal system from an arbitrary set of objects, some restrictive criteria are inserted;

e) a formal system is a syntactic system set apart from the formalized language, by eliminating semantic rules, or a syntactic system obtained from another syntactic system based on operations or a representation of a syntactic system. A potential formal system can be obtained from a syntactic system if it can get an interpretation. A characteristic of a formal system is that it can get an undefined number of interpretation, becoming a syntax for different languages (that are isomorph);

f) other criteria that impose restrictions: non-contradiction, completeness and independence.

An example of a formal system is the "the propositional calculus" built by Hilbert and Ackermann:

\section{1. primary object class:}

i. $\quad p, q, r$ : the variables category;

ii. $\quad-, v$ : the operators category;

iii. $\quad$, : the auxiliary symbol category;

\section{2. forming rules:}

i. variables are admitted sequences;

ii. if $\mathrm{A}$ is a sequence than $\overline{\mathrm{A}}$ is a sequence;

iii. if $\mathrm{A}, \mathrm{B}$ are sequences, $\mathrm{A} \vee \mathrm{B}$ is a sequence ( $\mathrm{A}$ and $\mathrm{B}$ are symbols for any sequences). Applying rule (ii) $p$ is a sequence, than $\bar{p}$ is also a sequence. Applying rule (iii) $p, \bar{p}$ are sequences, then $p \vee \bar{p}$ is also a sequence. Complicated sequences can be formed by the use of parenthesis: $p$ is a sequence, $q \vee \bar{q}$ is a sequence and therefore $p \vee(q \vee \bar{q})$ is also a sequence. Formal objects and sequences can be used in the formal system's language for renaming.

\section{3. axioms:}
i. $\overline{(\mathrm{p} \vee \mathrm{p})} \vee \mathrm{p}$;
ii. $\overline{\mathrm{p}} \vee(\mathrm{p} \vee \mathrm{q})$;
iii. $\overline{(p \vee q)} \vee(q \vee p)$;
iv. $\quad(\overline{\bar{p} \vee q}) \vee \overline{(r \vee p)} \vee(r \vee q)$;

\section{4. deduction rules:}

i. substitution rule;

ii. detaching rule: $\frac{\mathrm{A}, \overline{\mathrm{A} \vee \mathrm{B}}}{\mathrm{B}}$.

Language is a system of symbols handled after some rules with the aim of storing, pro-

cessing and transmitting information. This broader sense of the term language was im- 
posed by semiotic logic [6]. It refers to natural language (written or spoken) as well as specialized language (scientific or any other nature). Spoken languages are natural meanwhile written language is more artificial (deliberately built by people). From the semantic point of view the elements of a language are expressions, the basic expression being the statement. Languages can be classified by different criteria:

a) after physical nature of symbols: written or spoken;

b) after domain: universal or specialized;

c) after vocabulary nature: language with words (with alphabetical structure), ideographic language;

d) after precision: un-formalized or formalized;

e) after origin: natural or artificial.

For logics and mathematics a special interest represents ideographic languages (for example language of numbers, symbolic language in general). Symbols are elementary objects that express notions or concepts, or an auxiliary function with that scope. As opposed to words, that contain letters, symbols are simpler. They are much more precise and through combinations express clearly the relationships or the real structures. They detach the signification for which they are not used, for example emotional ones, even if not in an absolute way. The list of symbols, of formulas played an important role in the development of sciences, and civilization, in general. There are relationships between different forms of language, but they cannot be reduced one to another. The core of the human existence is natural language (and it's written equivalent) even though certain special languages, especially symbolic language, is an indispensable criteria for the development of civilization in general, and of sciences, in particular.

Tarski introduced the notion of formalized language in order to mark the differences between natural languages (spoken or written) and scientific languages, or, in a narrow sense, of deductive theories. The principles of constructing a language are:

1. given a set of elementary symbols (words);

2. given a list of operating rules for the symbols;

3. there exists a subset of language expressions organized in an axiomatic system.

Elementary symbols are divided into different categories (depending on the nature of the entities). Rules can be syntactic and semantic. Syntactic rules consist of forming, transforming or selection rules (deduction rules). Semantic rules consist of assigning and truth rules.

Rules are prescriptive meta-theoretical statements that handle symbols and expressions producing new expressions or statements, correctly built, that are true within the considered system. A rule prescribes a way of handling a class of operations. In a broader sense, a rule is synonym with a norm.

Rules can be written linear, under hypothetical form or as vertical sequences. For example: if $\mathrm{x} \rightarrow \mathrm{y}$ and $\mathrm{y} \rightarrow \mathrm{z}$ then $\mathrm{x} \rightarrow \mathrm{z}$ or $\frac{x \rightarrow y, y \rightarrow z}{x \rightarrow z}$. This rule is based on the logic rule: $(x \rightarrow y \& y \rightarrow z) \rightarrow(x \rightarrow z)$.

Definition is a statement or an ensemble of statements through which the meaning of a term is determined, or that indicates characteristic notes that can set a notion apart from another notion or the building way of a class of formal objects. The logic structure of a definition, regardless of her complexity, is A $=\mathrm{df} \mathrm{BC}$, where $\mathrm{A}$ is the entity to be defined, $\mathrm{BC}$ is the defining term, and $=\mathrm{df}$ is the definition relation. This reads as "is defined by" or "is equivalent by definition with" or "is identical through definition with". In this way, the formula $\mathrm{A}=\mathrm{df} \mathrm{BC}$ reads as " $\mathrm{A}$ is identical through definition with $\mathrm{BC}$ '[7].

Theorems are statements obtained from axioms or from previously built statements with the help of inference rules. The term postulate is used as a meaning for the set of thesis and rules initially admitted (axioms, definitions and rules). For example: axiom 1: the turnover of a firm has dropped in the last years; axiom 2: the profit and liquidity is diminishing, then theorem: if at a firm the turnover drops year by year, the profit and li- 
quidity is diminishing, then the firm is in difficulty (according to the diagnostic criteria). By deduction is meant applying inference rules on axioms or initially admitted statements a finite number of times.

Reasoning is a process of arriving from certain statements called premises to a statement called conclusion, so that if the premises are true, the conclusion is true or true with a great probability.

\section{Symbols' functions}

Economic symbols should have a precise significance, so that they are identically interpreted regardless the syntactic or pragmatic context. In general, symbols are used for generalizing logical operations, easier building of a proof or a theorem, edification of axiomatic language of economic sciences with all the advantages that follows from here (creation of an economic meta-science, developing of economic hermeneutics, unifying sciences, etc). There are multiple symbols' functions:

- Substitution function: the first function, an obvious one, derived from symbols' signification capacity to replace phenomena, processes, notions, categories, activities or symbols' properties. The semantic capacity of the symbols allows the interpreter to identify what the symbol substitutes, what is behind it, in order to further interpret the results of symbols forming and transforming rules.

- Information, communicative function: it is determined by the fact that any symbol transmits ideas, facts, and activities, has a certain informational loading. The interpreter must know both the semantic as well as contextual signification of the symbol, derived from the ensemble, from the system where it's used, in order to use the entire communicative capacity.

- Axiological function: is fulfilled only by the symbols that directly express a value, such as growing indicators, for example turnover (ICA), their average value $(\bar{c})$, the increase of the dimension of an activity $(\triangle \mathrm{CA}$ - turnover rise) etc. Forming and transforming rules can generate other val- ues, a new axiologic expression, to be certified by the interpreter.

- Normative function: is fulfilled only by those symbols that signifies certain requirements, notions, phenomena and economic processes restrictions such as efficiency normative (productivity, profitability etc.) that express a firm's minimum efficiency limit. For example, the symbol $\mathrm{kn} / 1000$ express the normative costs at 1000 lei production, a symbol used as a comparison term of similar calculated goods, determined effectively.

- Generalizing function: expressed by symbol's possibility to characterize a class of phenomena, processes and economic activities. Therefore, the symbol $\mathrm{Q}_{\mathrm{f}}$ generalizes the idea of manufactured production, obtained in all production systems. The symbol of money also assures a generalization and the iconic symbols of the brands signified the set of goods manufactured at that firm, etc.

- Logical function: expresses the possibility of using the symbols for different logic operations, for creating formal scientific languages, capable to drive a science to more abstract levels. With the help of symbols, a logical study of the set of expressions can be conducted, including the definition, classification, properties and syntactic relationships between expressions. The logical function of the symbol is given by the axiomatizing process, a tool of logics science that includes logic and the techniques of logic reasoning regarding syntax, semantic and pragmatic.

The advantage of formal representation is that there exists a set of rules called inference rules through which the facts known as true can be used in order to derive other facts that have to be true, also. Therefore, the truth about any new declaration can be verified in a certain manner related to the facts considered to be true. The most important feature of logic and formal systems is that the deductions are granted to be true. A reason for which the logic representation is used in the artificial intelligence domain is that the deriving of new facts based on old ones can be 
mechanized. Programs were written in order to automatically proof theorems using logical databases. If the number of facts increases very much, a combinatorial explosion appears and more relevant knowledge than necessary is available [8].

\section{Limits of the Formalized Axiomatic Sys- tems}

All axiomatic systems have their limitations inherited by the nature of formalisms. One of them, noted by A. N. Whitehead and B. Russell in "Principia Matematica" was that the substitution rule cannot be formalized [9]. The limitations that arise endanger the proof and the credibility of the formalized axiomatic system because it reveals the limitations of the tool used for building the system.

From the famous theorems of mathematical logic that reveal the limits of formalized axiomatic systems, the most important ones are:

- Gödel's first theorem - if a system is consistent, then it is incomplete, and always includes an un-provable formula $\mathrm{Aq}(\mathrm{q})$ (if the arithmetical formalized system is consistent, then $\mathrm{A}_{\mathrm{q}}(\mathrm{q})$ and $\sim \mathrm{A}_{\mathrm{q}}(\mathrm{q})$ cannot be proved).

- Gödel's second theorem - if the arithmetical formalized system is consistent, then a proof for the consistency cannot be built with the formalized tools provided by that system.

\section{Building the axiomatic system}

When formalizing and building an axiomatic system some steps have to be followed:

1. specifying the alphabet of the system;

2. inserting forming rules;

3. specifying the definitions;

4. defining the system's axioms;

5. inserting inference rules;

6. building theorems;

7. interpreting axioms and theorems.

Field of use - the system was intended for the economic field, but can be used in other fields.

System's potential - the system is developed in a various number of independent systems, depending only on the relationships between variables.
System's utility - the system was built in order to explain all possible correlations between indicators (quantitative and qualitative) of a firm. It can be used for:

- firm's diagnostic;

- elaborating firm's development strategies;

- real time decision making for all management functions;

- building expert systems.

System's limits - are the limits of formalized axiomatic systems.

\section{System's Alphabet}

Symbolizing the entire economic science field is a very difficult and hard to realize demarche. Our objective was to realize partial symbolizations that will be integrated into a general symbolic language. The symbols that are not contained in the alphabet are called meta-logic symbols. The alphabet together with the formulas forms the language.

1. variable symbols: $\mathrm{x}, \mathrm{y}, \mathrm{z}, \mathrm{x}_{1}, \mathrm{x}_{2}, \mathrm{x}_{11}, \mathrm{x}_{12}$;

2. logical connectors: \& (.), $\vee, \rightarrow, \vdash$;

3. symbols for parenthesis: ( left parenthesis, ) right parenthesis;

4. meta-logical symbols:

a. symbols for theorems: $\mathrm{T} 1, \mathrm{~T} 2, \ldots$;

b. symbols for axioms: A1, A2, ...;

5. symbols for parameters:

a. $\alpha, \beta, \delta, \gamma, \lambda, \mu, v, \eta, \imath, \chi, \varepsilon, \phi, \varphi, \pi, o$, $\rho, \sigma, \omega, \alpha \mathrm{i}, \beta \mathrm{i}, \delta \mathrm{i}, \gamma \mathrm{i}, \phi \mathrm{i}, \alpha \mathrm{ij}, \beta \mathrm{ij}, \delta \mathrm{ij}$, $\gamma \mathrm{ij}$;

b. the general symbol for a parameter: PR;

6. meta-logical symbols - for arithmetic language:

a. [ symbol that marks the beginning of a comment;

b. ] symbol that marks the ending of a comment;

c. = binary predicative symbol $[=\mathrm{x}, \mathrm{y}$ reads as $\mathrm{x}$ equals $\mathrm{y}$;

d. $<$ binary predicative symbol $[<\mathrm{x}, \mathrm{y}$ reads as $\mathrm{x}$ less than $\mathrm{y}$;

e. + tertiary predicative symbol $[+(\mathrm{x}, \mathrm{y}$, $\mathrm{z}$ ) reads as $\mathrm{x}+\mathrm{y}=\mathrm{z}$;

f. $\times$ tertiary predicative symbol $[\times(x, y$, $\mathrm{z}$ ) reads as $\mathrm{x} \times \mathrm{y}=\mathrm{z}$; 
g. =df symbol for definition $[A=d f B$ reads as $\mathrm{A}$ is defined by $\mathrm{B}$ ];

7. symbols for expressing trends:

a. $\uparrow$ or + the factor's trend is to increase;

b. $\downarrow$ or - the factor's trend is to decrease;

c. $0 \sim \mathrm{t}$ the factor's value modifies on the time interval $0, t$;

8. relationships symbols: $\mathrm{RV}=$ "+", " $\vee "$,

$$
\text { ,-,", "<", ":",; }
$$

9. modal symbols: $\square$ (must), $\diamond$ or $\mathrm{M}$ (is possible).

\section{Forming rules}

Forming rules are the forming rules of formal logic.

\section{Definitions}

1. $\mathrm{x} \times \mathrm{y}=\mathrm{z}=\mathrm{df} \times(\mathrm{x}, \mathrm{y}, \mathrm{z})$

2. $x+y=z \quad=d f+(x, y, z)$

3. $x-y=z=d f-(x, y, z)$

4. $\mathrm{x}: \mathrm{y}=\mathrm{z} \quad=\mathrm{df}:(\mathrm{x}, \mathrm{y}, \mathrm{z})$

$$
\mathrm{x} \times \mathrm{y}=\mathrm{z} \&
$$

5. $\left.x_{1} \times x_{2}=x \&\right\}=d f \times\left(\times\left(\times\left(x_{11}, x_{12}, x\right), x_{2}, x\right), y, z\right)$ or the general form:

$\mathrm{x}_{11} \times \mathrm{x}_{12}=\mathrm{x}_{1}$

a. $\left(\mathrm{x}_{\mathrm{RV}} \mathrm{y}=\mathrm{z}\right) \&\left(\mathrm{x}_{1} \mathrm{RV} \mathrm{x}_{2}=\mathrm{x}\right) \&\left(\mathrm{x}_{11} \mathrm{RV} \mathrm{x}_{12}=\mathrm{x}_{1}\right)$

b. $=\operatorname{df} R V\left(\operatorname{RV}\left(R V\left(x_{11}, x_{12}, x\right), x_{2}, x\right), y, z\right)$

6. modus pones rule:

$(\mathrm{x} \rightarrow \mathrm{y} \& \mathrm{y} \rightarrow \mathrm{z}) \rightarrow(\mathrm{x} \rightarrow \mathrm{z})$

7. adjunction in conjunction rule:

$\mathrm{x} \vdash \mathrm{y}$ and $\mathrm{y}{ }^{\vdash} \mathrm{z}$ then $\mathrm{x} \vdash \mathrm{y}, \mathrm{z}$

8. conjugating premises rule:

$x \rightarrow(y \rightarrow z)$, then $(x \& y) \rightarrow z$

9. commutation premises rule: $\mathrm{z} \rightarrow(\mathrm{y} \rightarrow \mathrm{x}) \equiv \mathrm{y} \rightarrow(\mathrm{z} \rightarrow \mathrm{x})$

\section{Rules for variables}

\section{a. Subtraction rules $-(\mathbf{x}, \mathbf{y}, \mathbf{z})$ :}

$$
\begin{aligned}
& \text { R1: } \square \mathrm{x} \uparrow \alpha \rightarrow\left(\mathrm{y} \uparrow \rho_{1} \rightarrow \mathrm{z} \uparrow \rho_{1}{ }^{*}\right) \\
& \text { R2: } \square \mathrm{x} \uparrow \alpha \rightarrow\left(\mathrm{y}^{\mathrm{c}} \rightarrow \mathrm{z} \uparrow \rho_{2}{ }^{*}\right) ; \\
& \text { R3: } \square \mathrm{x} \uparrow \alpha \rightarrow\left(\mathrm{y} \uparrow \rho_{3} \rightarrow \mathrm{z} \downarrow \rho_{3}{ }^{*}\right) \\
& \text { R4: } \square \mathrm{x} \uparrow \alpha \rightarrow\left(\mathrm{y} \downarrow \rho_{4} \rightarrow \mathrm{z} \uparrow \rho_{4}{ }^{*}\right) ;
\end{aligned}
$$

reads as:

R1: IF $\mathrm{x}$ is growing with $\alpha$ THEN $\mathrm{z}$ is growing with $\rho_{1}{ }^{*}$ if $\mathrm{y}$ is growing with $\rho_{1}$;

R2: IF $\mathrm{x}$ is growing with $\alpha$ THEN $\mathrm{z}$ is growing with $\rho_{2}{ }^{*}$ if $\mathrm{y}$ stays constant;

R3: IF $\mathrm{x}$ is growing with $\alpha$ THEN $\mathrm{z}$ is decreasing with $\rho_{3}{ }^{*}$ if $\mathrm{y}$ is growing with $\rho_{3}$;

R4: IF $\mathrm{x}$ is growing with $\alpha$ THEN $\mathrm{z}$ is growing with $\rho_{4}{ }^{*}$ if $\mathrm{y}$ is decreasing with $\rho_{4}$.

where $\alpha>1, \rho_{1}>1, \rho_{1}{ }^{*}=\frac{\alpha x-\rho_{1} y}{x-y}, \rho_{1}<\frac{(\alpha-1) x+y}{y}, \rho_{2}<1, \rho_{2}{ }^{*}=\frac{\alpha x-y}{x-y}, \rho_{3}>1$,

$$
\rho_{3}{ }^{*}=\frac{\alpha x-\rho_{3} y}{x-y}, \rho_{3}>\frac{(\alpha-1) x+y}{y}, \rho_{4}<1, \rho_{4}{ }^{*}=\frac{\alpha x-\rho_{4} y}{x-y} .
$$

\section{b. Multiplying rules * $(x, y, z)$ :}
R5: $\square \mathrm{x} \uparrow \alpha \rightarrow\left(\mathrm{y} \uparrow \beta_{1} \rightarrow \mathrm{z} \uparrow \beta_{1}^{*}\right)$;
R6: $\square \mathrm{x} \uparrow \alpha \rightarrow\left(\mathrm{y}^{\mathrm{c}} \rightarrow \mathrm{z} \uparrow \beta_{2}{ }^{*}\right)$;
R7: $\square \mathrm{x} \uparrow \alpha \rightarrow\left(\mathrm{y} \downarrow \beta_{3} \rightarrow \mathrm{z} \downarrow \beta_{3}{ }^{*}\right)$;
R8: $\square \mathrm{x} \uparrow \alpha \rightarrow\left(\mathrm{y} \downarrow \beta_{4} \rightarrow \mathrm{z} \uparrow \beta_{4}{ }^{*}\right)$;

where $\alpha>1, \beta_{1}>1, \beta_{1}{ }^{*}=\alpha \beta_{1}, \beta_{1}{ }^{*}=\alpha, \beta_{3}<1, \alpha \beta_{3}<1, \beta_{3}{ }^{*}=\alpha \beta_{3}, 0<\beta_{4}<1, \alpha \beta_{4}>1$, 
$\beta_{4}{ }^{*}=\alpha \beta_{4}$

c. Adding rules $+(\mathbf{x}, \mathbf{y}, \mathbf{z})$ :

R9: $\square \mathrm{x} \uparrow \alpha \rightarrow\left(\mathrm{y} \uparrow \chi_{1} \rightarrow \mathrm{z} \uparrow \chi_{1}^{*}\right)$;

R10: $\square \mathrm{x} \uparrow \alpha \rightarrow\left(\mathrm{y}^{\mathrm{c}} \rightarrow \mathrm{z} \uparrow \chi_{2}^{*}\right)$;

R11: $\square \mathrm{x} \uparrow \alpha \rightarrow\left(\mathrm{y} \downarrow \chi_{3} \rightarrow \mathrm{z} \uparrow \chi_{3}{ }^{*}\right)$;

$\mathbf{R} 12 \square \mathrm{x} \uparrow \alpha \rightarrow\left(\mathrm{y} \downarrow \chi_{4} \rightarrow \mathrm{z} \downarrow \chi_{4}^{*}\right) ;$

where $\alpha>1, \chi_{1}>1, \chi_{1}^{*}=\frac{\alpha x+\chi_{1} y}{x+y}, \chi^{2}=\frac{\alpha x+y}{x+y}, \chi_{3}<1, \chi^{*}=\frac{x(1-\alpha)+y}{y}$,

$\frac{\mathrm{x}(1-\alpha)+\mathrm{y}}{\mathrm{y}}<\chi_{3}, \chi_{4}<1, \chi_{4}{ }^{*}=\frac{\mathrm{x}(1-\alpha)+\mathrm{y}}{\mathrm{y}}, \chi_{4}<\frac{\mathrm{x}(1-\alpha)+\mathrm{y}}{\mathrm{y}}$.

\section{d. Dividing rules :(x,y,z):}

R13: $\square \mathrm{x} \uparrow \alpha \rightarrow\left(\mathrm{y} \uparrow \tau_{1} \rightarrow \mathrm{z} \uparrow \tau_{1}^{*}\right) ;$

R14: $\square \mathrm{x} \uparrow \alpha \rightarrow\left(\mathrm{y}^{\mathrm{c}} \rightarrow \mathrm{z} \uparrow \tau_{2}{ }^{*}\right)$;

$\mathbf{R} 15 \square \mathrm{x} \uparrow \alpha \rightarrow\left(\mathrm{y} \uparrow \tau_{3} \rightarrow \mathrm{z} \downarrow \tau_{3}{ }^{*}\right) ;$

R16: $\square \mathrm{x} \uparrow \alpha \rightarrow\left(\mathrm{y} \downarrow \tau_{4} \rightarrow \mathrm{z} \uparrow \tau_{4}{ }^{*}\right) ;$

where $\alpha>1, \tau_{1}>1, \tau_{1}{ }^{*}=\frac{\alpha}{\tau_{1}}, \alpha>\tau_{1}, \tau_{3}>1, \tau_{2}{ }^{*}=\alpha, \tau_{3}{ }^{*}=\frac{\alpha}{\tau_{3}}, \alpha<\tau_{3}, \tau_{4}<1, \tau_{4}{ }^{*}=\frac{\alpha}{\tau_{4}}$.

\section{Building Axioms}

\section{Inductive Method}

A1:

\begin{tabular}{|ll}
\hline$\times(\mathbf{x}, \mathbf{y}, \mathbf{z}) \rightarrow$ & $\left(\square \mathbf{z} \uparrow \alpha \rightarrow \diamond\left(\left(\mathbf{y} \uparrow \beta^{*} \rightarrow \mathbf{x} \uparrow \beta\right) \vee\left(y \downarrow \delta^{*} \rightarrow \mathbf{x} \uparrow \delta\right) \vee\right.\right.$ \\
& $\left.\left.\vee\left(y \uparrow \gamma^{*} \rightarrow \mathbf{x} \downarrow \gamma\right) \vee\left(y \uparrow \alpha \rightarrow x^{c}\right) \vee\left(y^{\mathrm{c}} \rightarrow \mathbf{x} \uparrow \alpha\right)\right)\right)$
\end{tabular}

where

$$
\alpha>1, \beta>1, \beta \neq 0, \beta^{*}=\frac{\alpha}{\beta}, \beta^{*}>1, \delta>1, \delta \neq 0, \delta^{*}=\frac{\alpha}{\delta}, \delta^{*}<1, \gamma<1, \gamma \neq 0, \gamma^{*}=\frac{\alpha}{\gamma}, \gamma^{*}>1 \text {. }
$$

A2:

$$
\begin{aligned}
+(\mathbf{x}, \mathbf{y}, \mathbf{z}) \rightarrow \quad & \left(\square \mathbf { z } \uparrow \alpha \rightarrow \diamond \left(\left(\mathbf{y} \uparrow \chi^{*} \rightarrow \mathbf{x} \uparrow \chi\right) \vee\left(\mathbf{y} \downarrow \varepsilon^{*} \rightarrow \mathbf{x} \uparrow \varepsilon\right) \vee\right.\right. \\
& \left.\left.\left.\vee\left(\mathbf{y} \uparrow \phi^{*} \rightarrow \mathbf{x} \downarrow \phi\right)\right) \vee\left(\mathbf{y} \uparrow \alpha_{11} \rightarrow \mathbf{x}^{\mathbf{c}}\right) \vee\left(\mathbf{y}^{\mathbf{c}} \rightarrow \mathbf{x} \uparrow \boldsymbol{\alpha}_{12}\right)\right)\right)
\end{aligned}
$$

where $\alpha>1, \chi>1, y \neq 0, y>0, \chi^{*}=\alpha+(\alpha-\chi) \frac{x}{y}, \chi^{*}>1, \varepsilon>1, \quad \varepsilon^{*}=\alpha+(\alpha-\varepsilon) \frac{x}{y}, \varepsilon^{*}<1, \varepsilon>\varepsilon^{*}, \phi<1$,

$$
\phi^{*}=\alpha+(\alpha-\phi) \frac{\mathrm{x}}{\mathrm{y}}, \phi^{*}>1, \phi<\phi^{*}, \alpha_{11}=\alpha+(\alpha-1) \frac{\mathrm{x}}{\mathrm{y}}, \alpha_{11}>1, \mathrm{x} \neq 0, \alpha_{12}=\alpha+(\alpha-1) \frac{\mathrm{y}}{\mathrm{x}},
$$

$\alpha_{12}>1$.

A3:

$$
\begin{aligned}
-(\mathbf{x}, \mathbf{y}, \mathbf{z}) \rightarrow \quad & \left(\square \mathbf { z } \uparrow \alpha \rightarrow \diamond \left(\left(\mathbf{y} \uparrow \rho^{*} \rightarrow \mathbf{x} \uparrow \rho\right) \vee\left(\mathbf{y} \downarrow \sigma^{*} \rightarrow \mathbf{x} \uparrow \sigma\right) \vee\right.\right. \\
& \left.\left.\left.\vee\left(\mathbf{y} \downarrow \omega^{*} \rightarrow \mathbf{x} \downarrow \omega\right)\right) \vee\left(\mathbf{y} \downarrow \alpha_{21} \rightarrow x^{c}\right) \vee\left(y^{c} \rightarrow \mathbf{x} \uparrow \alpha_{22}\right)\right)\right)
\end{aligned}
$$

where $\alpha>1, y \neq 0, \rho>1, \rho^{*}=\alpha+(\rho-\alpha) \frac{x}{y}, \rho^{*}>1, \rho>\rho^{*}, \sigma>1, \sigma^{*}=\alpha+(\sigma-\alpha) \frac{x}{y}, \sigma^{*}<1, \omega<1$, $\omega^{*}=\alpha+(\omega-\alpha) \frac{\mathrm{x}}{\mathrm{y}}, \omega^{*}>\omega, \omega^{*}<1, \alpha_{21}=\alpha+(1-\alpha) \frac{\mathrm{x}}{\mathrm{y}}, \alpha_{21}<1, \mathrm{x} \neq 0, \alpha_{22}=\alpha+(1-\alpha) \frac{\mathrm{y}}{\mathrm{x}}$, $\alpha_{22}>1$.

A4:

$$
\begin{aligned}
:(\mathbf{x}, \mathbf{y}, \mathbf{z}) \rightarrow \quad & \left(\square \mathbf { z } \uparrow \alpha \rightarrow \diamond \left(\left(\mathbf{y} \uparrow \varphi^{*} \rightarrow \mathbf{x} \uparrow \varphi\right) \vee\left(\mathbf{y} \downarrow \pi^{*} \rightarrow \mathbf{x} \uparrow \pi\right) \vee\right.\right. \\
& \left.\left.\vee\left(\mathbf{y} \uparrow \mathbf{o}^{*} \rightarrow \mathbf{x} \downarrow \mathbf{0}\right) \vee\left(\mathbf{y} \uparrow \alpha_{31} \rightarrow \mathbf{x}^{\mathbf{c}}\right) \vee\left(\mathbf{y}^{\mathbf{c}} \rightarrow \mathbf{x} \uparrow \alpha\right)\right)\right)
\end{aligned}
$$


where $\alpha>1, \varphi>1, \varphi^{*}=\frac{\varphi}{\alpha}, \varphi^{*}>1, \pi^{*}=\frac{\pi}{\alpha}, \pi^{*}<1, \mathrm{o}^{*}=\frac{\mathrm{o}}{\alpha}, \mathrm{o}^{*}>1, \alpha_{31}=\frac{1}{\alpha}, \alpha_{31}<1$.

\section{Deductive method}

A5:

$$
\begin{aligned}
& \times(\mathbf{x}, \mathbf{y}, \mathbf{z}) \rightarrow \quad\left(\square \mathbf { x } \uparrow \alpha \rightarrow \diamond \left(\left(\mathbf{y} \uparrow \beta_{1} \rightarrow \mathbf{z} \uparrow \beta_{1}{ }^{*}\right) \vee\left(y^{\mathrm{c}} \rightarrow \mathbf{z} \uparrow \beta_{2}{ }^{*}\right) \vee\right.\right. \\
& \left.\left.\vee\left(\mathbf{y} \downarrow \beta_{3} \rightarrow \mathbf{z} \downarrow \beta_{3}{ }^{*}\right) \vee\left(y \downarrow \beta_{4} \rightarrow \mathbf{z} \uparrow \beta_{4}{ }^{*}\right)\right)\right)
\end{aligned}
$$

where $\alpha>1, \beta_{1}>1, \beta_{1}{ }^{*}=\alpha \beta_{1}, \beta_{1}{ }^{*}=\alpha, \beta_{3}<1, \alpha \beta_{3}<1, \beta_{3}{ }^{*}=\alpha \beta_{3}, 0<\beta_{4}<1, \alpha \beta_{4}>1, \beta_{4}{ }^{*}=\alpha \beta_{4}$.

A6:

$$
\begin{aligned}
+(\mathbf{x}, \mathbf{y}, \mathbf{z}) \rightarrow \quad & \left(\square \mathbf { x } \uparrow \alpha \rightarrow \diamond \left(\left(\mathbf{y} \uparrow \chi_{1} \rightarrow \mathbf{z} \uparrow \chi_{1}^{*}\right) \vee\left(\mathbf{y}^{\mathbf{c}} \rightarrow \mathbf{z} \uparrow \chi_{2}{ }^{*}\right) \vee\right.\right. \\
& \left.\left.\vee\left(\mathbf{y} \downarrow \chi_{3} \rightarrow \mathbf{z} \uparrow \chi_{3}^{*}\right) \vee\left(\mathbf{y} \downarrow \chi_{4} \rightarrow \mathbf{z} \downarrow \chi_{4}^{*}\right)\right)\right)
\end{aligned}
$$

where $\alpha>1, \chi_{1}>1, \chi_{1}{ }^{*}=\frac{\alpha x+\chi_{1} y}{x+y}, \chi_{2}{ }^{*}=\frac{\alpha x+y}{x+y}, \chi_{3}<1, \chi^{*}=\frac{x(1-\alpha)+y}{y}$,

$$
\frac{\mathrm{x}(1-\alpha)+\mathrm{y}}{\mathrm{y}}<\chi_{3}, \chi_{4}<1, \chi^{*}=\frac{\mathrm{x}(1-\alpha)+\mathrm{y}}{\mathrm{y}}, \chi_{4}<\frac{\mathrm{x}(1-\alpha)+\mathrm{y}}{\mathrm{y}} \text {. }
$$

A7:

$$
\begin{aligned}
-(x, y, z) \rightarrow \quad & \left(\square \mathbf { x } \uparrow \alpha \rightarrow \diamond \left(\left(y \uparrow \rho_{1} \rightarrow z \mathbf{z} \rho_{1}{ }^{*}\right) \vee\left(y^{c} \rightarrow z^{c} \rho_{2}{ }^{*}\right) \vee\right.\right. \\
& \left.\left.\vee\left(y \uparrow \rho_{3} \rightarrow z \downarrow \rho_{3}{ }^{*}\right) \vee\left(y \downarrow \rho_{4} \rightarrow z \rho_{4}{ }^{*}\right)\right)\right)
\end{aligned}
$$

where $\alpha>1, \rho_{1}>1, \rho_{1}{ }^{*}=\frac{\alpha x-\rho_{1} y}{x-y}, \rho_{1}<\frac{(\alpha-1) x+y}{y}, \rho_{2}<1, \rho_{2}{ }^{*}=\frac{\alpha x-y}{x-y}, \rho_{3}>1, \rho_{3}{ }^{*}=\frac{\alpha x-\rho_{3} y}{x-y}$,

$$
\rho_{3}>\frac{(\alpha-1) x+y}{y}, \rho_{4}<1, \rho_{4}{ }^{*}=\frac{\alpha x-\rho_{4} y}{x-y} .
$$

A8:

$$
\begin{gathered}
:(\mathbf{x , y}, \mathbf{z}) \rightarrow \quad\left(\square \mathbf { x } \uparrow \alpha \rightarrow \diamond \left(\left(\mathbf{y} \uparrow \tau_{1} \rightarrow \mathbf{z} \uparrow \tau_{1}{ }^{*}\right) \vee\left(\mathbf{y}^{\mathrm{c}} \rightarrow \mathrm{z} \uparrow \tau_{2}{ }^{*}\right) \vee\right.\right. \\
\left.\left.\vee\left(\mathbf{y} \uparrow \tau_{3} \rightarrow \mathbf{z} \downarrow \tau_{3}{ }^{*}\right) \vee\left(\mathbf{y} \downarrow \tau_{4} \rightarrow \mathbf{z} \uparrow \tau_{4}{ }^{*}\right)\right)\right)
\end{gathered}
$$

where $\alpha>1, \tau_{1}>1, \tau_{1}^{*}=\frac{\alpha}{\tau_{1}}, \alpha>\tau_{1}, \tau_{3}>1, \tau_{2}^{*}=\alpha$, $\tau_{3}^{*}=\frac{\alpha}{\tau_{3}}, \alpha<\tau_{3}, \tau_{4}<1, \tau_{4}^{*}=\frac{\alpha}{\tau_{4}}$.

It can be noted that in both cases of induction or deduction there are four main axioms that are called standard axioms, that reflects the system's invariance. They are constant for the four arithmetical operations: +,,- :, $\times$. With the help of those eight axioms, all possible solutions can be obtained, for the variables in that specific configuration. Practically, the axiomatic system is capable to express all possible relationships between economic and efficiency indicators of a firm. Based on the indicators system, the correspondent axiom is used and the theorem system is built.
9 Determining the Alternatives Systems Based on the Symbols (Operators) Between Variables

The semantic tree method is an automatic method of semantic analysis, which consists of determining the logical values of subformulas of the given formula. It reduces complexity through the elimination of logical constants (truth-functional connectives and quantifiers) and places sub-formulas of a considered formula on branches of a semantic tree. The semantic tree method is a very interesting and universal method. It forms an important part of the mechanization of reasoning [9]. In figure 1 it is presented the general form of a left decomposed binary tree. 


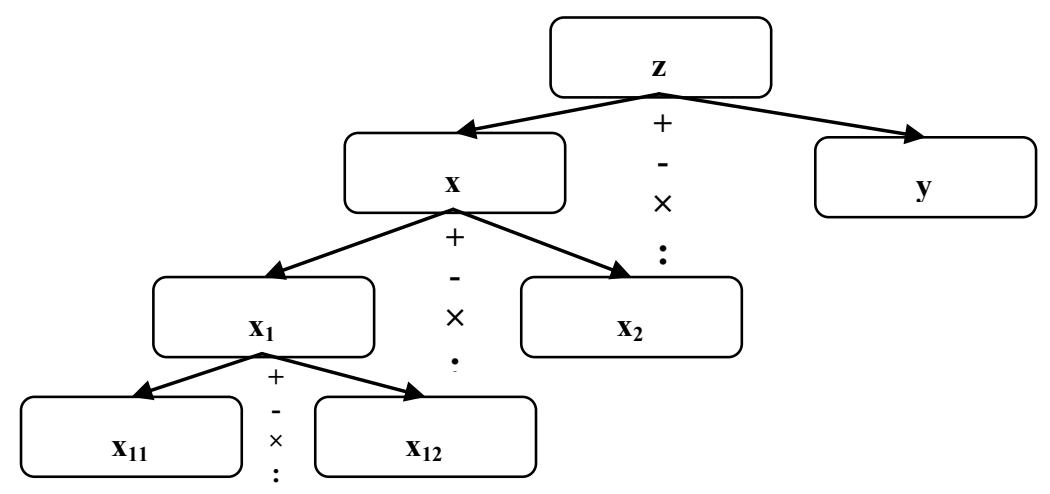

Fig. 1. Representing knowledge with the use of semantic trees

Starting from the initial node $\mathrm{z}$, the target to be obtained, using inductive rules, criteria can be found to determine the change in $\mathrm{z}$ based on the changes in the dependent variables $\mathrm{x}$ and $\mathrm{y}$. As an example, the system with the multiplying symbol (operator) $\times\left(\times\left(\times\left(\mathrm{x}_{11}, \mathrm{x}_{12}, \mathrm{x}_{1}\right), \mathrm{x}_{2}, \mathrm{x}\right), \mathrm{y}, \mathrm{z}\right)$ is considered, where $\mathrm{z}$ is a very well determined target: $\mathrm{z}=$ $\mathrm{f}\left(\mathrm{x}_{11}, \mathrm{x}_{12}, \mathrm{x}_{2}, \mathrm{y}\right)$. Therefore, five theorems can be obtained, based on the axiom A1, describing the five possibilities of changing the value of $z$.

T 1. $\quad \mathrm{z} \uparrow \alpha \rightarrow\left(\mathrm{y} \uparrow \beta^{*} \rightarrow \mathrm{x} \uparrow \beta\right)$ that reads as: if ,z" have to grow with $\alpha$ then it is possible that , $\mathrm{x}$ " to grow with $\beta$ if , y" grows with $\beta^{*}$

T 2. $\square \mathrm{z} \uparrow \alpha \rightarrow\left(\mathrm{y} \downarrow \delta^{*} \rightarrow \mathrm{x} \uparrow \delta\right)$

\section{T 3. $\square \mathrm{z} \uparrow \alpha \rightarrow\left(\mathrm{y} \uparrow \gamma^{*} \rightarrow \mathrm{x} \downarrow \gamma\right)$}

T 4. $\quad \mathrm{z} \uparrow \alpha \rightarrow\left(\mathrm{y} \uparrow \alpha \rightarrow \mathrm{x}^{\mathrm{c}}\right)$

\section{T 5. $\square \mathrm{z} \uparrow \alpha \rightarrow\left(\mathrm{y}^{\mathrm{c}} \rightarrow \mathrm{x} \uparrow \alpha\right)$}

where: $\alpha>1, \beta>1, \beta \neq 0, \beta^{*}=\frac{\alpha}{\beta}, \beta^{*}>1, \delta>1$, $\delta \neq 0, \delta^{*}=\frac{\alpha}{\delta}, \delta^{*}<1, \gamma<1, \gamma \neq 0, \gamma^{*}=\frac{\alpha}{\gamma}, \gamma^{*}>1$.

Based on the axioms, 105 theorems can be developed, continuing to find alternatives for $\mathrm{x}$, then for $\mathrm{x}_{1}$. Each theorem proposes an al- ternative of obtaining the target " $\mathrm{z}$ has to grow with $\alpha$ ". The logic of building the theorems is: at the first level, the raise of " $z$ " with " $\alpha$ " can be achieved with the help of variables " $x$ " and " $y$ " with the following alternatives: both " $x$ " and " $y$ " grow, but both growing rates are lower than " $\alpha$ ", but enough to ensure the target growth; " $\mathrm{x}$ " is growing and " $y$ " is diminishing, but the grow in " $x$ " should compensate the diminishing in " $y$ " and to assure the growing rate; " $y$ " is growing and " $\mathrm{x}$ " is diminishing, but the diminishing in " $x$ " has to be compensated with the growth in " $y$ " and to ensure the target growth ; " $y$ " is growing with" $\alpha$ " and " $x$ " is constant; " $x$ " is growing with " $\alpha$ " and " $y$ " stays constant; at the second level, the growth or decrease in " $x$ " affects " $x_{1}$ ", respectively " $x_{2}$ "; at the third level, the growth or decrease in " $\mathrm{x}_{1}$ " affects " $\mathrm{x}_{11}$ ", respectively " $\mathrm{x}_{12}$ ".

\section{Examples}

The following system grasps the influences between a firm's indicators with a multiplication relationship. For example, the semantic tree for the turnover - figure 2 . If we consider $\mathrm{z}=$ turnover $(\mathrm{CA}), \mathrm{x}=$ manufactured production (PF), $\mathrm{y}=$ capitalization manufacturing production degree (GVPF), $\mathrm{x}_{1}=$ labor productivity $(\mathrm{PM}), \mathrm{x}_{2}=$ number of workers (NS), $x_{11}=$ technical endowment degree (GVT), $x_{12}=$ return on assets (RA). 


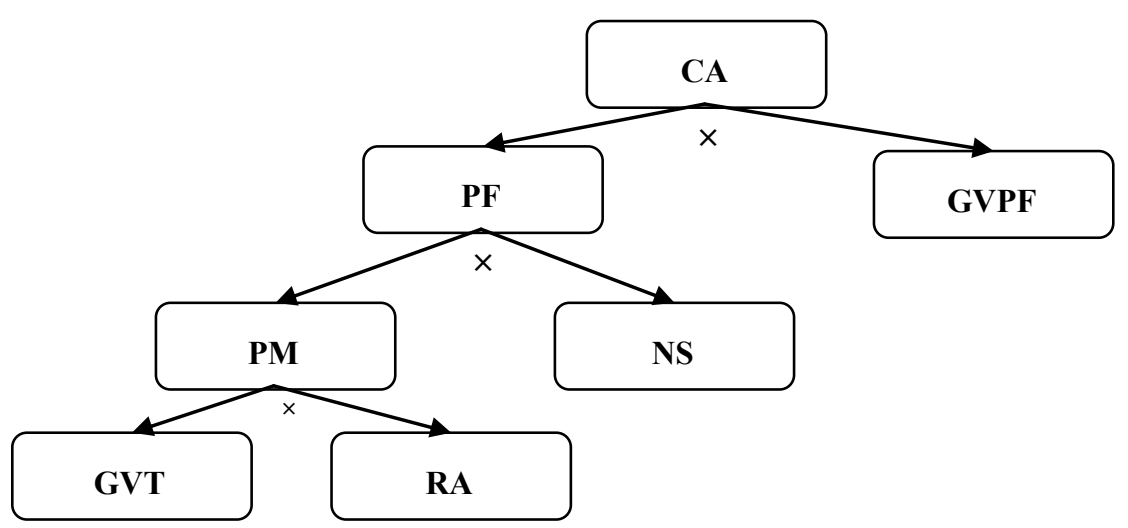

Fig. 2. The semantic tree for the turnover

From the methodological point of view, because of the system's properties, it's not important if the variable is work productivity or total asset capitalization, the relationship between variables is important. Because of this characteristic, the axiomatic system built is very general.

Semantic trees can be used separately, when they are completely independent, or can be integrated by addition.

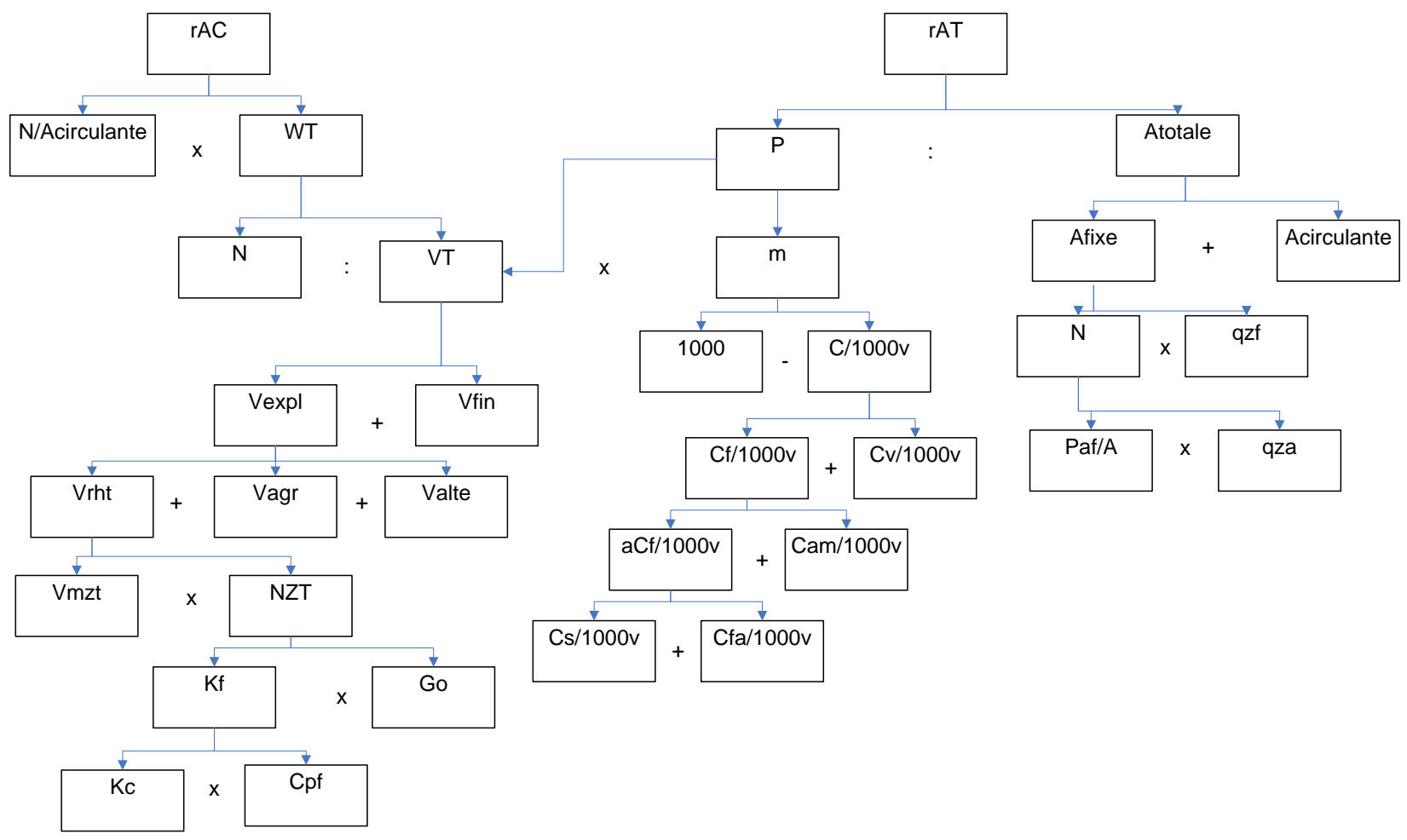

Fig. 3. The semantic tree for circulating and total assets capitalization

The system presented in figure 3 sets the targets for three main variables: the income generated from the hotel activities, restaurant and treatment (Vrht); the expenditure for 1000 lei income $(\mathrm{C} / 1000 \mathrm{v})$ and the total assets (Atotale). Circulating assets capitalization (rAC) and total asset capitalization
(rAT) are the desired indicators, but they rely on those three main indicators. For those main variables semantic trees were used in order to obtain the axioms and the theorems. The other variables change their value depending on these main variables. NZT = number of tourist days; Vmzt $=$ average in- 
come on a tourist day; $\mathrm{Kf}=$ using capacity; Go = occupying level; Kc = touristic built capacity; $\mathrm{Cpf}=$ putting to function coefficient; $\mathrm{Cf} / 1000 \mathrm{v}=$ fixed expenditures for 1000 lei income; $\mathrm{Cv} / 1000 \mathrm{v}=$ variable expenditures for 1000 lei income; $\mathrm{aCf} / 1000 \mathrm{v}=$ fixed expenditures 1000 lei income, other than amortization; Cam $/ 1000 \mathrm{v}=$ amortization expenditure for 1000 lei income; $\mathrm{Cs} / 1000 \mathrm{v}=$ wages expenditures for 1000 lei income; $\mathrm{Cfa} / 1000 \mathrm{v}=$ other expenditures for 1000 lei income; Afixe =fixed assets; Acirculante $=$ circulating assets; $\mathrm{N}=$ average personnel number; qzf $=\mathrm{Af} / \mathrm{N}=$ degree of endowment with fixed assets $\mathrm{Af} / \mathrm{N}$; paf $/ \mathrm{A}=$ Af $/$ Atotale $=$ weight of fixed assets in total assets; qza $=\mathrm{A} / \mathrm{N}=$ degree of endowment with total assets; Vagr = income from leisure; Valte = income from other activities; Vexpl = operating income; Vfin $=$ financial income; $\mathrm{VT}=$ total income; $\mathrm{WT}=$ work productivity; $\mathrm{rAC}=$ circulating assets capitalization; $\mathrm{P}=$ profit; $\mathrm{m}=\mathrm{P} /$ Vtotale $=$ weighted profit; $\mathrm{rAT}=\mathrm{P} /$ Atotale $=$ total assets capitalization.

As a reasoning method deduction can be used (beginning at the bottom level, if the value of building capacity is changed, how that change affects all the variables until it reaches circulating asset capitalization) and induction (e.g. - setting a target for total asset capitalization, the system will determine the values for all the other variables in order to sustain that target).

To build a generally valid system (a formalized one) it is necessary to create an interconnected system of indicators, the advantage being that if the value of one indicator is changing, the values of the other indicators depending on it will also be updated automatically.

\section{Conclusions}

Steps have been made in order to transcend the natural language and achieve a symbolic axiomatic language. Economic sciences have known an obvious evolution in the last century; beginning to use axiomatic methods, applying mathematical instruments as a decision-making tool. This paper proposes a for- malized approach to business growth, based on mathematics and logics, taking into consideration the particularities of the economic sector.

Decision support systems can be built based on the theorems that can be translated into procedures and used for building a webbased application that could be available online for paying users that need What-If analysis. Another usage would be in the field of expert system. One of the limitations of the proposed system is that it is reduced to the arithmetical operations of adding, multiplying, dividing and subtracting.

Given the current business/economic and regulatory environment in developing countries, the opportunity costs of informality seem to be much lower than the cost of operating formally, but the benefit of using a formalized system is greater than the effort of implementing it.

\section{References}

[1] http://oxforddictionaries.com/definition/ english/axiom? $\mathrm{q}=$ axiom

[2] http://dexonline.ro/definitie/axiom $\% \mathrm{C} 4$ $\% 83$

[3] C. Popa, Teoria cunoaşterii - perspectivă semiotico-praxiologică asupra actului cunoaşterii, Bucureşti: Editura Ştiinţifică, 1972

[4] Gh. Băileşteanu and D. Târnăveanu, Axiomatică Economică, Timişoara: Editura Mirton, 2008

[5] Gh. Enescu, Dicţionar de logică, Bucureşti: Editura Tehnică, pag. 36

[6] Gh. Băileşteanu, Semiotica Economică, Timişoara: Editura Mirton, 2005

[7] Dictionary, p.96

[8] P. A., Tacu, R. Vancea, Ş. Holan, A. Burciu, Inteligenţa artificială. Teorie şi aplicaţii în economie, Editura Economică, 1998

[9] Gh. Băileşteanu, Logică Economică, Timişoara: Editura Mirton, 2004

[10] I. Bondecka-Krzykowska - Semantic tree method - historical perspective and applications, Annales UMCS Informatica AI 3, pp. 15-25, 2005 


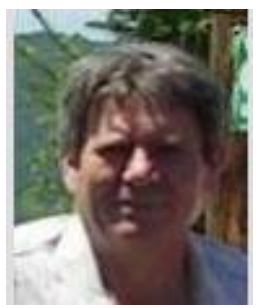

Gheorghe BĂILEŞTEANU has graduated the Faculty of Economic Sciences, West University of Timişoara in 1976. He joined the staff of the Faculty of Economics and Business Administration as a teaching assistant in 1980 and had gone through all didactic positions (lecturer, senior lecturer, assistant professor and full professor). He holds an Academy of Economic Studies' $\mathrm{PhD}$ diploma in Economics since 1989. Currently he is full professor within the Department of Management, Faculty of Economics and Business Administration, West University of Timişoara and since 1999 he is a $\mathrm{PhD}$ coordinator on Management. In 2008 he was named emeritus professor by the Economic Sciences Faculties Association of Romania - AFER. He is the author of 23 economics and management books, 3 literature and philosophy books and over 80 journal or conference volume articles. His work focuses on the firms' management and economic theory.

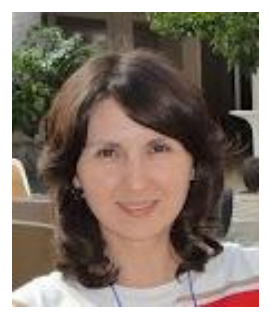

Diana TÂRNĂVEANU has graduated the Faculty of Mathematics from the West University of Timişoara in 1995. She holds a PhD diploma in Management from 2008. Currently she is lecturer of Economic Informatics within the Department of Business Information Systems at Faculty of Economics and Business Administration from the West University of Timişoara. She is teaching advances in database management systems, business intelligence and decision support systems. She is the author of 10 books and over 40 journal articles in the field of Knowledge Management, Decision Support Systems, Collaborative Systems and Business Intelligence. 